\section{Organometallic Vapor-Phase Epitaxy: Theory and Practice G.B. Stringfellow}

(Academic Press, 1989), 393 pages

ISBN: 0-12-673840-8

As the semiconductor industry moves toward novel devices like multiple quantum well lasers, surface emitting lasers, high-speed heterojunction bipolar transistors and long-wavelength photodiodes, organometallic vapor-phase epitaxy (OMVPE) is becoming an attractive crystal growth technique for fabricating these structures. This recent attractiveness is due partly to the availability of commercial OMVPE reactors, the simplicity of process operation, and OMVPE process's scalability from the developmental laboratory to the manufacturing environment. This book is timely in that it is the first to present the subject of OMVPE in a logical and concise manner.

The author, G.B. Stringfellow, is a full professor at the University of Utah in the Departments of Materials Science and Engineering and Electrical Engineering. In a discipline that is approximately 20 years old, Stringfellow has been a noted authority in this field for more than 10 years. He is credited for much of the seminal work involving the understanding of the kinetics of the OMVPE growth process, much of which is described throughout his book.

The book is written for graduate and undergraduates, as well as scientists and technicians familiar with this field. The material is presented in a very clear, nonobfuscating style and can be comprehended by those who may have only a superficial interest in the subject. The author starts every chapter with a basic introduction to each subject and then cites specific examples. This book most certainly should be used as a primary reference in any short course on OMVPE, and should be on every crystal grower's shelf. The book is an excellent accompaniment to the proceedings of the International Conference on Metallorganic Vapor Phase Epitaxy, which are published every two years.

Stringfellow's book is organized into nine chapters as follows: OMVPE process overview, OMVPE sources, thermodynamics, kinetics, hydrodynamics and mass transport, design of the OMVPE process, specific materials, superlattice structures, and devices. Chapter 1, the introduction, gives the reader a brief precis of the subject and describes and compares other epitaxial techniques. The author also takes the time to familiarize the reader with the many acronyms used for OMVPE precursors, as well as those associated with the OMVPE process (this author prefers MOCVD).
Chapter 2, on OMVPE sources, is well written in that it introduces the reader to the chemistry involved in the process. As a physical chemist, I found the discussion involving bond energies, molecular symmetry, and precursor pyrolysis to be refreshing. The "chemical aspect" of OMVPE has always been largely ignored by physicists, electrical engineers, and materials scientists who dominate this field of crystal growth. Starting with this chapter and continuing throughout the book, Stringfellow gives credence to the chemistry as well as the physics of the OMVPE process. Such acknowledgment enhances the book's intellectual value.

Chapters 3 and 4 on thermodynamics and kinetics, respectively, give a good overview of these areas as they relate to the OMVPE process. Highlights in Chapter 3 include discussion on the valence force field model on crystal bond lengths, phase diagrams for several material systems, and thermodynamic factors affecting dopant incorporation. Items in Chapter 4 include rate constants for several homogeneous and heterogeneous reactions. An in-depth survey of pyrolysis reactions for different precursors is also included.

Chapters 5 and 6 extend the reader's knowledge to the subjects of hydrodynamics mass transport and the design of the OMVPE process, respectively. An excellent discussion of the boundary-layer model ensues, as well as literature citations for the different temperature and pressure regimes for OMVPE. Chapters 7, 8, and 9 concentrate on specific materials, superlattice structures, and devices, respectively. These chapters are the most helpful to the investigator interested in a particular material system or device; the cited references are up-to-date and serve as good starting points. Chapter 8 , on superlattice structures, does not include much on InP-based alloys used for multiple quantum well structures, surface emitters, or InGaAs strained transmitters. However, these topics as well as a more detailed discussion of devices fabricated by OMVPE should be the subject of a second edition.

In conclusion, I highly recommend this text as a primary reference. As when many areas of science reach a certain level of maturity, laboratory notes become technical papers and technical papers become the "good books" on the subject. Stringfellow's OMVPE: Theory and Practice is one of the first "good books" in this field.

Reviewer: Victor R. McCrary is a member of technical staff at ATET Bell Laboratories in Murray Hill, NJ. He is responsible for the crystal growth of multiple quantum lasers by lowpressure MOCVD.

\section{Small Particles and Inorganic Clusters \\ Edited by C. Chapon, M.F. Gillet, and \\ C.R. Henry \\ (Springer-Verlag, 1989), 612 pages \\ ISBN: 3-540-51390-6}

This book is the proceedings of the Fourth International Meeting on Small Particles and Inorganic Clusters, held at University Aix-Marseille III, Aix-en-Provence, France, July 1988. The book contains approximately 130 papers, most of which can be roughly divided into two categories: gas-phase cluster research and condensedphase metal particle research. These are currently vital research areas, so the book is certainly timely.

The book is mainly intended for scientists working in the area of cluster research. Because of the multidisciplinary nature of this research area, an important function of the book is to develop a common language and a better mutual understanding for all researchers involved in the various aspects of the effort. For materials scientists interested in compacting clusters into solids, several articles on the sources of the clusters, as well as the section on the cluster structures will be useful. But overall, the emphasis of the book is not on materials research.

The book is organized into seven sections: (1) formation, (2) atomic structures, (3) dynamics, (4) stability and fragmentation, (5) electronic structures and properties, (6) optical properties, and (7) adsorption and chemical reactions. Because of the diverse nature of the papers, it is not an easy job to organize them into a coherent book. Sometimes the categorization is arbitrary. For example, some of the articles in section one are more related to other subjects than the formation of the clusters.

The qualities of the papers are usually good. A large percentage of the contributions came from Europe, presumably because of the location of the conference. The development of new cluster sources, new instrumental and computational techniques, and the magic numbers problem seemed to have been the main theme of the conference.

In summary, this is a useful book for scientists interested in fundamental cluster research, but is not for those only interested in assembling clusters into materials.

Reviewer: $Y$. Wang is in the Central Research Department at E.I. du Pont de Nemours \& Co. His research interests include nanometer-sized semiconductor clusters, nonlinear optical properties of materials, and excited state dynamics. 


\section{VCH Publishers Presents...}

\section{MATERIALS SCIENCE AND TECHNOLOGY}

A Comprehensive Treatment

Editors-in-Chlef

R.W. Cahn, Cambridge, UK

P. Haasen, Göttingen, Germany

E.J. Kramer, Cornell, USA

The first comprehensive reference series to cover the entire range of materials systematically according to subject. Each topic-oriented volume includes contributions from more than 200 leading scientists from throughout the world. The editors and authors of Materials Science and Technology provide an authoritative, in-depth coverage of their areas of expertise. It is a thoroughly referenced series with indexes in all volumes and a cumulative index for the entire series. It will be of interest to scientists and engineers from such diverse disciplines as physics, metallurgy, chemistry, ceramic and polymer science and technology, chemical engineering, energy technology, electronics and electrical engineering, and medical physics.

Materials Sclence and Technology will comprise of 18 hardcover volumes, each containing 10 to 20 chapters. At least four volumes will be published each year, and the series will be completed in 1994. Volume 5 , Phase Transformations in Materials, will be the first volume published, appearing in May, 1991.

\section{Future Volumes}

Volume 1: Structure of Solids, edited by V. Gerold (Stuttgart, FRG), 0-89573-689-6

Volume 2: Characterization of Materials, edited by E. Lifshin (Schenectady, USA), 0-89573-690-X

Volume 3: Electronic and Magnetic Properties of Metals and Ceramics, edited K.H.J. Buschow (Eindhoven, The Netherlands), 0-89573-691-8

Volume 4: Electronlc Structure and Properties of Semiconductors, edited by W. Schroter (Göttingen, FRG), 0-89573-692-6

Volume 5: Phase Transformations In Materials, edited by P. Haasen (Göttingen, FRG), 0-89573-693-4

Volume 6: Plastic Deformation and Fracture of Materials, edited by Mughrabi (Erlangen, FRG), 0-89573-694-2

Volume 7: Constitution and Properties of Steels, edited by J.B.

Pickering (Sheffield, UK), 0-89573-695-0

Volume 8: Structure and Properties of Nonferrous Alloys, edited by K.H. Matucha (Frankfurt, FRG), 0-89573-696-9

Volume 9: Glasses and Amorphous Materials, edited by J. Zarzycki (Montpellier, France), 0-89573-697-7

Volume 10: Nuclear Materials, edited by B.R.T. Frost (Argonne, USA), 0-89573-698-5

Volume 11: Structure and Properties of Ceramics, edited by M.

Swain (Sydney, Australia), 0-89573-699-3

Volume 12: Structure and Properties of Polymers, edited by E.L.

Thomas (Cambridge, USA), 0-89573-700-0

Volume 13: Structure and Properties of Composites, edited by T.W. Chou (Delaware, USA), 0-89573-800-7

Volume 14: Medical and Dental Materials, edited by D.F. Williams (Liverpool, UK), 0-89573-801-5

Volume 15: Processing of Metals and Alloys, edited by R.W. Cahn (Cambridge, UK), 0-89573-802-3

Volume 16: Processing of Semiconductors, edited K.A. Jackson (Tucson, USA), 0-89573-803-1

Volume 17: Processing of Ceramles, edited by R.J. Brook (Stuttgart, FRG), 0-89573-804-X

Volume 18: Processing of Polymers, edited by M. Gottlieb (BeerSheva, Israel), 0-89573-805-8

\section{INTERNATIONAL ENCYCLOPEDIA OF COMPOSITES}

Editor

Stuart M. Lee, editor of the SAMPE Journal This remarkable six volume set is the first and only reference source to consult when seeking an overvicw of any topic in composites technology. Its 4000 pages contain over 240 original and completely up-to-date articles. Over 300 distinguished researchers, theoreticians, applications and hands-on international technologists have contributed and made this the most comprehensive, authoritative and accurate work of its kind. Topics covered: Composites Processes including Automation, Braiding, Casting, Chemical Vapor Infiltration, Conventional Fabrication, Extrusion Infiltration, Joining, Machining, Molding, Prepregging, Pulformin Gpultrusion, Rapid Solidification, Robotics,Radiation, Squeeze Casting. Thermoforming and Weaving. Will be of special interest to materials scientists, engincers, analysts, chemists, designers, physicists, fabricators, technical professionals, user of composites in any industry, and scientific and technical libraries.

Series ISBN 0-89573-290-4

Price per volume: $\$ 275.00$ Subscription: $\$ 235.00$ Send for a complete brochure.

Just Published

Volume 3 JOINING, ADHESIVES, TO METAL MATRIX COMPOSITES

1990 0-89573-733-7 Cloth 526pp

Volume 4 MICROMECHANISMS OF MODE I AND MODE II FRACTURE TO POLYMERIC EXTRUSIONS

1990 0-89573-734-5 Cloth 532pp

\section{ADVANCED MATERIALS}

Editor

Peter Gölitz

The journal emphasizes an interdisciplinary approach to all its contributions and seeks to help the physicist and chemist to learn from each other and for all to communicate with the materials scientist. Advanced Materials covers all aspects of materials science but especially genuinely new materials and methods for their preparation, modification, and investigation.

Published monthly ISSN: 0935-9648 Institutional Subscription: \$245.00 Individual Subscription: $\$ 120.00$

- Customer Service Inquirles:

VCH 303 NW 12th Ave

Deerfield Beach FL 33442

In the US: $800 \cdot 422 \cdot 8824$

Outside the US: $305 \cdot 428 \cdot 5566$

(8:30 • 4:45 EST.)

$\$$ Outside of North America,

Contact: VCH PO Box 10-11-61

D-6940 Weinheim, Germany 


\title{
Announcing the \\ INTERNATIONAL CONFERENCE ON METALLURGICAL COATINGS AND THIN FILMS
}

\author{
April 22-26, 1991 \\ San Diego, Callfornia \\ Sponsored by: Vacuum Metallurgy Division, American Vacuum Soclety \\ Thin Film Division, American Vacuum Society
}

The premiere annual conference on the science, technology, and engineering applications of coatings, thin films, and modified surfaces produced by the various deposition or surface treatment techniques designed to modify the properties of materials. This is the conference that provides you with maximum VALUE for your meeting attendance budget. It is an optimum size with no more than six simultaneous sessions in a compact convention center that permits quick transfer between sessions--no 2000 people running into each other, and no 20 sessions to run between. Plus all fully paid registrants will receive a three-volume proceedings of REFEREED, type-set papers--not a camera-ready book thrown together.

A. Coatings for Use at High Temperatures

- Over sixty papers on thermal barrier coatings, coatings for composites, and coatings to resist high temperature wear and corrosion.

- Selected invited papers:

1. "The Mechanical Behavior of Coated Materials Used for Aero Engine Turbine Blade Applications," T. Rhys-Jones

2. "High Temperature Erosion Resistance of Coatings for Use in Gas Turbine Engines," W. Tabakoff

B. Hard Coatings

- Over eighty papers on technology and properties of PVD and CVD hard coatings

- Selected invited papers:

1. "Laser-assisted CVD of Hard and Refractory Binary Compounds," M. Boman and J.-O. Carlsson 2. "Macroparticle Contamination in Cathodic Arc Coatings: Generation, Transport, and Control," R. L. Boxman

C. Thin Films for Microelectronics and High

Tempera ture Superconductors

- Over sixty papers on VLSI materials, heterostructures, superlattices, transpont phenomena, laser ablation and sensors. Plus fwenty-seven papers on high-Tc films.

- Selected invited papers:

I. "Laser Ablation for High Temperature Superconductor Multilayer Devices," K. Char 2. "Growth and Properties of Thermodynamically Stable Epitaxial Bured Metallic Layers in Compound Semiconductors," C. J. Palmstrom et al.

D. Diamond and Related Materials

- Over sixty papers on synthesis of diamond films electronic and industrial applications of diamond, and cubic boron nitride.

- Selected invited papers:
I. "Characterization of Semiconducting Diamond Films and Its Application to Electronic Devices," K. Okano

2. "CVD Diamond Growth With Halocarbons," R. H. Hauge et al.

E. Tribological Coatings/Surface Modifications

- Over eighty papers on friction-reducing films, wear- resistant ceramic-, metallic-, and composite coatings, erosion-resistant coatings, mechanlcal processes at the nanometer scale, and tribology of diamond films

- Selected invited papers:

I. "Theoretical Microscopic Studies of Kinetic Friction," J. B. Sokoloff

2. "Friction and Wear Properties of Diamonds and Diamond Coatings," I.P. Hayward

F. Optical Coatings, Magneto-Optics, and Guided Waves

- Over thirty papers on thin optical films and magneto-optic and phase change recording materials and devices

- Selected invited papers:

I. "Ion-Assisted Deposition of Optical Coatings," B. G. Bovard

2. "Thin-Film Requirements for Optical Waveguides - Materials and Processes," B. Kurdi

G. Methods for Characterizing Films and Modified Surfaces

- Over forty papers on thin film analysis technlques, microstructural characterization, and nondestructive characterization.

- Selected invited papers:

I. "Surface Arialysis of Internal Interfaces Using Conversion Electron Mossbauer Spectroscopy," B. Tatarchuk

2. "Imaging Metal Overlayers on Metal Surfaces Using Scanning Tunneling Microscopy," R. J.Wilson

\section{OTHER CONFERENCE HIGHLIGHTS}

- Workshop on Current Topics in Advanced PVD Technology for Optical and Wear Resistant Applications. Speakers include D. Mattox, R. Howson, B. Window, P. Martin, J. Musil, and W.-D. Munz. To be held on Sunday, April 21.

- Special Session on Industrial Equipment and Applications. Seventeen presentations by companies and organizationsdesigned to present information of a commercial nature on the latest products and processes related to coatings and films. To be held on April 22 and 23.

- Exhibits. Approximately fifty companies will be exhibiting their products that will feature equipment for deposition and monitoring of coatings and films, vacuum equipment, and surfaceanalysis instrumentation.

- Short Courses. One-day courses will be held on: (I) Plasma-Enhaniced CVD, (2) Sputter Deposition, (3) Adhesion of Metallic and Polymeric Thin Films, and (4) Structure-Propeity Relations in Thin Films.

- Banquet on evening of April 24.

To receive a complimentary copy of the Preliminary Program with Registration Information, write to: Bruce D. Sartwell, General Chairman, Naval Research Laboratory, Code 4675, Washington, DC 20375. Or send a telefax request to (202) 767-5301. 